\title{
GASTOS COM A ROTATIVIDADE DE FUNCIONÁRIOS NA CONSTRUÇÃO CIVIL: ESTUDO DE CASO NO VALE DO CAÍ/RS ${ }^{1}$
}

\section{COSTS OF EMPLOYEE TURNOVER IN BRAZILIAN CONSTRUCTION: A CASE STUDY IN THE CAÍ VALLEY}

\section{COSTOS DE ROTACIÓN DE EMPLEADOS EN CONSTRUCCIÓN BRASILEÑA: UN ESTUDIO DE CASO EN EL VALLE DEL CAÍ}

\begin{abstract}
Alex Eckert, Doutor em Administração pela Universidade de Caxias do Sul (UCS) em associação ampla com a Pontifícia Universidade Católica do Rio Grande do Sul (PUCRS).

Endereço Profissional: Universidade de Caxias do Sul (UCS), Rua Francisco Getúlio

Vargas,1130, B. Petrópolis, Caxias do Sul, RS - Brasil, CEP 95070560. Telefone: (054)

32182267. URL da Homepage: http://www.ucs.br. E-mail: aeckert@ucs.br
\end{abstract}

Fernanda Maldaner, Bacharel em Ciências Contábeis pela Universidade de Caxias do Sul (UCS). Endereço Profissional: Instituto Federal de Educação, Ciência e Tecnologia do Rio Grande do Sul (IFRS) - Campus Feliz, Rua Princesa Isabel 60, Vila Rica - Feliz/RS - Brasil, CEP 95770000. Telefone: (051) 36374416. E-mail: fernanda.maldaner@ feliz.ifrs.edu.br.

Marlei Salete Mecca, Doutora em Engenharia da Produção pela Universidade Federal de Santa Catarina (UFSC). Endereço Profissional: Universidade de Caxias do Sul (UCS), Rua Francisco Getúlio Vargas, 1130, B. Petrópolis, Caxias do Sul, RS - Brasil, CEP 95070560. Telefone: (054) 32182267. URL da Homepage: http://www.ucs.br. E-mail:

msmecca@ucs.br.

Roberto Biasio, Doutor em Administração pela Universidade Federal do Rio Grande do Sul (UFRGS). Endereço Profissional: Universidade de Caxias do Sul (UCS), Rua Francisco Getúlio Vargas, 1130, B. Petrópolis, Caxias do Sul, RS - Brasil, CEP 95070560. Telefone: (054) 32182267. URL da Homepage: http://www.ucs.br. E-mail: rbiasio@ ucs.br.

\section{RESUMO}

O presente estudo traz como tema principal a rotatividade de funcionários, fenômeno este que vem afetando praticamente todos os setores em decorrência do alto custo gerado e também pelo transtorno causado no processo de reposição. Diante disso, o objetivo do estudo é analisar seu impacto nos gastos de uma empresa do ramo da construção civil, localizada no Vale do Caí/RS. O procedimento metodológico utilizado para o desenvolvimento da pesquisa foi o estudo de caso, expondo os objetivos de modo descritivo e abordando o problema de forma qualitativa. A coleta de dados ocorreu em evidências documentais, registros em arquivos, entrevistas informais e observações diretas. Os resultados encontrados indicam que os índices de rotatividade na empresa em estudo, motivados principalmente pelas ofertas mais atrativas de emprego, estão relativamente altos em comparação aos do setor da construção civil brasileira. Além disso, constatou-se que os principais gastos com a rotatividade são aqueles que envolvem o desligamento, a reposição e o treinamento. Caso a empresa obtivesse

\footnotetext{
1 Artigo submetido em 22/01/2016, revisado em 21/01/2017, aceito em 03/03/2017 e divulgado em 01/07/2017 pelo Editor João Carlos Hipólito Bernardes do Nascimento, após double blind review.
}

GєCont, v. 4, n. 1, Floriano-PI, Jan-Jun. 2017. 
êxito na diminuição dos índices de rotatividade, os valores gastos nesses processos poderiam permanecer na empresa, beneficiando, diretamente e indiretamente, tanto os proprietários quanto os próprios funcionários.

Palavras-chave: Rotatividade; Causas da rotatividade; Índices de rotatividade; Gastos.

\begin{abstract}
This study has as its main theme employee turnover, a phenomenon that is affecting virtually all sectors due to the high cost generated as well as the inconvenience caused in the replacement process. Thus, the aim of the study is to analyze its impact on spending a Brazilian construction company, located in the Cai Valley. The methodological procedure used for the development of the research was the case study, outlining the goals and descriptive way of addressing the problem in a qualitative way. The data collection occurred on documentary evidence, files, informal interviews and direct observations. The results indicate that the turnover rates in the company under study, mainly motivated by more attractive offers of employment are relatively high compared to the Brazilian civil construction sector. Furthermore, it were found that the major expenses rotation are those that involve shutdown, reset and training. If the company were successful in reducing turnover rates, the amounts spent on these processes could stay in business, benefiting, directly and indirectly, both the owners and the employees themselves.
\end{abstract}

Keywords: Turnover; Causes of turnover; Turnover rates; Costs.

\title{
RESUMEN
}

Este estudio tiene como principal tema de la rotación de personal, un fenómeno que está afectando a prácticamente todos los sectores debido a los altos costos generados, así como las molestias causadas en el proceso de sustitución. Así, el objetivo del estudio es analizar su impacto en el gasto de una empresa de construcción brasileña, ubicada en Valle del Caí. El procedimiento metodológico utilizado para el desarrollo de la investigación fue el estudio de caso, delineando los objetivos y forma descriptiva de abordar el problema de una manera cualitativa. La recolección de datos ocurrió en pruebas documentales, archivos, entrevistas informales y observaciones directas. Los resultados indican que las tasas de rotación en la empresa objeto de estudio, motivado principalmente por ofertas más atractivas de empleo son relativamente altos en comparación con el sector de la construcción civil brasileña. Además, se encontró que la mayor rotación de los gastos son aquellos que implican el apagado, reset y la formación. Si la compañía tuvo éxito en la reducción de las tasas de rotación, los montos gastados en estos procesos podrían permanecer en el negocio, beneficiando, directa e indirectamente, tanto los propietarios y los propios trabajadores.

Palabras clave: Rotación de empleados; Las causas de la rotación; Las tasas de rotación; Gasto.

\section{INTRODUÇÃO}

Em um mercado de trabalho competitivo e em regime de ofertas intensas, conforme cita Chiavenato (2006), costuma ocorrer um aumento da rotatividade de pessoal, sendo que pode escapar do controle da organização o crescimento no volume dos desligamentos. Observa-se que esta rotatividade de pessoas vem sendo tema de preocupação e discussão no mercado. De acordo com Dias (2014), o crescimento da rotatividade advém do aumento da geração de empregos no Brasil, onde o trabalhador, buscando uma melhor colocação de trabalho, migra de emprego. 
Segundo Chiavenato (2006), quando a rotatividade de funcionários ocorre e não é de iniciativa da organização, torna-se essencial localizar os motivos que provocam a evasão de recursos humanos, a fim de que a organização possa atuar sobre eles e diminuir o volume dos expurgos indesejáveis. $\mathrm{O}$ autor reforça ainda que, além dos inúmeros aspectos negativos, a rotatividade a médio e longo prazo provoca enormes prejuízos à organização, ao mercado, à economia e também para o empregado. Para Campos e Malik (2008), estudos mostram que, quando o nível de rotatividade considerado adequado a uma organização se encontra acima de $26 \%$, produz altos custos e impactos financeiros. Para estes autores, quando este indicador fica acima de $50 \%$, corre-se o risco de comprometer a produtividade e a qualidade.

Conforme o Departamento Intersindical de Estatística e Estudos Socioeconômicos em seu Boletim Trabalho e Construção (DIEESE, 2011), a rotatividade de funcionários é um problema que atinge todo o mercado de trabalho brasileiro, apontando o Brasil como o segundo país que apresenta o mais baixo tempo médio de permanência no trabalho entre 25 países. Ainda segundo este boletim, o ramo da construção civil é o setor que apresenta a maior taxa de rotatividade entre os trabalhadores.

Ribeiro (2011) salienta que a indústria da construção civil mostrou nos últimos anos um crescimento significativo junto ao mercado econômico, impulsionada pela boa fase da economia nacional nos anos anteriores e principalmente pelo Programa de Aceleração do Crescimento - PAC, Copa do mundo de 2014 e Olimpíadas em 2016. Para este autor, o aquecimento no ramo da construção estimula a rotatividade de pessoas, por diminuir a oferta de profissionais qualificados em relação à demanda exigida, valorizando os cargos e as funções. Conclui este autor, afirmando que os custos não esperados e os atrasos nos prazos previstos em cronograma geram transtornos às empresas.

Portanto, acredita-se que o presente estudo seja relevante perante o atual cenário econômico do Brasil, tendo em vista que as organizações têm demonstrado grande preocupação com o gerenciamento dos custos sobre os bens e serviços produzidos, conforme Cardoso, Cardoso e Santos (2013). Assim, o presente estudo versa sobre a rotatividade de funcionários, fazendo um levantamento dos gastos que podem decorrer da evasão não prevista de colaboradores, que por sua vez, crê-se ser um fator determinante para a diminuição da lucratividade da empresa. Diante disso, o objetivo deste estudo é verificar qual seu impacto nos gastos de uma empresa do ramo da construção civil do Vale do Caí/RS.

\section{REFERENCIAL TEÓRICO}

\subsection{Rotatividade de funcionários}

Acredita-se que o crescimento econômico brasileiro visto nos últimos anos incentivou o surgimento de milhares de novos empregos, valorizando os profissionais qualificados e aumentando a remuneração pelos serviços prestados. Conforme Eckert et al (2011), quando há muitas vagas de trabalho disponíveis, aumenta-se a busca por melhores salários e oportunidades, estimulando os funcionários a trocarem de emprego. Sendo assim, pressupõese que o principal impasse do rápido crescimento é a falta de profissionais disponíveis para cobrir as vagas de trabalho oferecidas no mercado. Segundo os mesmos autores, sobrando vagas, os profissionais buscam melhores oportunidades e mais benefícios salariais, acarretando na alta rotatividade de funcionários, denominado também turnover.

Chiavenato (2004) destaca que a rotatividade representa a constante entrada e saída de pessoas da organização, seja voluntária ou involuntariamente. Para Pontes (2001), a dinâmica de entrada e saída de pessoal em uma organização é chamada de Rotação de Recursos Humanos, flutuação, ou ainda turnover. 
São diversas as fórmulas utilizadas para o cálculo da rotatividade, possibilitando assim, avaliar a situação da empresa. Segundo Chiavenato (2010) uma das fórmulas leva em consideração o número de pessoas que se desligaram num determinado período de tempo e o número médio de colaboradores existentes. Outra fórmula, de acordo com Pontes (2001), leva em consideração a média entre as demissões e as admissões de pessoal em determinado período. Além delas, em nível governamental a fórmula mais utilizada é a do DIEESE (2014), que utiliza utilizam o valor mínimo entre admitidos e desligados, relacionando-os ao "estoque" médio de empregados de cada período.

Medeiros, Alves e Ribeiro (2012) salientam que pode haver vários possíveis motivos influenciadores da rotatividade de funcionários, tais como: a satisfação dos colaboradores, a motivação, a remuneração e recompensas, e até mesmo o processo de seleção e recrutamento realizado pela empresa.

Para Chiavenato (2009), o salário pago em relação ao cargo ocupado, constitui apenas uma parcela dos custos relacionados ao pacote de compensações que as empresas absorvem para manter o pessoal dentro de uma organização. Já para Silva (2001), o ambiente de trabalho não pode ser negligenciado, visto que as condições de trabalho serão um fator cada vez mais relevante para o recrutamento e retenção de pessoal. Além disso, percebe-se que o grau de instrução vem se mostrando também um indicador que eleva a rotatividade de funcionários. De acordo com Gonzaga (1998), quando existe uma alta taxa de rotatividade há um incentivo à informalização na relação de trabalho, uma vez que o trabalhador migra de emprego em emprego, as empresas optam em informalizar a relação empregado/empresa, eximindo-se do custo da admissão e verbas rescisórias.

Nota-se que os efeitos da rotatividade afetam também a qualidade e o desempenho na área produtiva. Gonzaga (1998) salienta que como a rotatividade da mão de obra é elevada, as empresas investem pouco em treinamentos, gerando um limitado aumento na produtividade. $\mathrm{O}$ autor enfatiza que o treinamento promovido pelas empresas é um investimento de alto risco, tendo em vista que é incerto o retorno desse investimento no futuro, além de ter a possibilidade de o funcionário carregar consigo o capital humano desenvolvido dentro da empresa para outro emprego.

\subsection{Gastos com a rotatividade de funcionários}

De acordo com Frezzati (2008), os recursos necessários para as operações numa organização implicam em gastos, que pode ser conceituado como sendo um sacrifício de valor para obtenção de produtos ou serviços, representado pela promessa ou entrega de ativos. Para Eckert et al. (2011), a contabilidade, enquanto ciência que estuda os atos e fatos de uma organização, deve estar integrada à área de recursos humanos para apurar os custos deste setor e contribuir na tomada de decisões. Conforme Cardoso, Cardoso e Santos (2013), a apuração do custo é fundamental para o processo de controle, avaliação de desempenho e tomada de decisão.

Além disso, verifica-se que a falta de controle dos custos incorridos na área de recursos humanos reflete diretamente no resultado da empresa. Percebe-se que a falta de controle dos custos incorridos com a rotatividade e absenteísmo, além da falta de análise da influência destes sobre o custo do produto, pode resultar em uma redução nos resultados da empresa, pois além de reduzir a margem de lucro sobre o produto em função da elevação no custo, e por conseguinte estar perdendo espaço no mercado para seus concorrentes que conseguem ofertar o mesmo produto a um custo menor (CARDOSO; CARDOSO; SANTOS, 2013).

Consonante a isso, Silva (2001) alerta que o custo financeiro é talvez a consequência organizacional mais representativa dentro de uma organização e mesmo assim, são poucas as 
empresas que avaliam os custos diretos e indiretos. Pontes (2001) salienta que os administradores devem se preocupar com a rotação de pessoas, ao passo que além dos custos financeiros, relacionados com as novas admissões de pessoal e com os desligamentos, há também outros custos, mais difíceis de serem mensurados, como o custo com a integração e treinamento de novos funcionários.

Segundo Mariano e Mayer (2008), o efeito mais evidente da rotatividade de pessoal é justamente o aumento de custos, que podem ser divididos em quatro categorias tangíveis: custos de recrutamento e seleção, custos de admissão e treinamento, custos de desligamento e de recolocação. Já Cascio e Boudreau (2010), dividem a mensuração dos custos com rotatividade em três grandes categorias de custos: custos de desligamento, de reposição e de treinamento.

\subsection{Rotatividade de funcionários no setor da construção civil}

Conforme boletim divulgado pelo DIEESE (2012), a construção civil ocupa um contingente crescente de trabalhadores e é apontada como uma das responsáveis pelo dinamismo econômico e do mercado de trabalho nos últimos anos. Segundo este órgão, a construção é indicada como a primeira colocada no ranking da taxa de rotatividade global, onde as taxas são superiores a 100\% nos períodos analisados (2002 a 2012).

Acredita-se que são vários os fatores relacionados à rotatividade de funcionários na construção civil. Conforme a Central dos Sindicatos Brasileiros (CSB, 2012), a alta rotatividade na construção se deve principalmente pelo ciclo natural do processo produtivo do setor, uma vez que, ao se concluir uma obra em determinado local, nem sempre se permanece com o mesmo quadro de funcionários numa obra nova, em razão da distância. Ainda, de acordo com CSB, o setor da construção civil é considerado de baixa qualificação de mão de obra, e por este motivo, o empresário não sente necessidade em mantê-lo.

Uma das grandes consequências do aquecimento do mercado da construção civil tem sido a escassez da mão de obra, capacitada, para atender a demanda do setor (MARCONDES, 2011). De acordo com Müller (2013), um dos maiores desafios que a economia brasileira encontrará nos próximos anos está relacionado à crescente escassez de profissionais qualificados, uma vez que a oferta destes profissionais é inferior à demanda exigida pela indústria. Segundo o autor, no ramo da construção civil, 63,6\% dos empresários classificam a falta de qualificação como sendo um dos principais impasses encontrado pelo setor.

\section{METODOLOGIA}

Quanto aos procedimentos técnicos, foi realizado um de estudo de caso. Na visão de Yin (2010), o estudo de caso é o método utilizado quando o enfoque está sobre um fenômeno contemporâneo no contexto da vida real, onde se busca responder às questões "como" e "por que". Já em relação aos objetivos, foi utilizada a pesquisa descritiva, buscando estabelecer uma relação entre os custos decorrentes da rotatividade de funcionários e o impacto desta na rentabilidade de uma empresa societária. Na concepção de Gil (2010), a pesquisa descritiva tem como principal objetivo descrever características de determinada população e grupo ou ainda, identificar possíveis relações entre as variáveis.

Quanto à forma de abordagem do problema, trata-se de pesquisa qualitativa. Segundo Richardson (1999), os estudos que empregam uma metodologia qualitativa podem descrever a complexidade de determinado problema e analisar a interação de certas variáveis. Diante das colocações dos autores, entende-se que as metodologias escolhidas são as mais adequadas para o tipo de estudo proposto. 
A coleta de dados ocorreu mediante a utilização de diversos meios. Inicialmente foram coletadas evidências documentais e registros em arquivos de documentos relativos às admissões e demissões ocorridos na empresa objeto do estudo. Além disso, foram realizadas entrevistas informais com os gestores e outros atores envolvidos na gestão dos recursos humanos da empresa, complementadas por observações diretas realizadas pelos próprios pesquisadores.

\section{ANÁLISE DA ROTATIVIDADE NA EMPRESA OBJETO DO ESTUDO}

\subsection{Apresentação da empresa}

O estudo foi realizado numa empresa do ramo da construção civil, localizada na região do Vale do Caí/RS. Fundada no ano de 2000, trabalha exclusivamente com obras públicas, através de processos licitatórios. Para fins de teste de estudo, a empresa será chamada de FM (nome fictício). Ela executa diversos tipos de serviços na construção civil, dentre eles, elaboração de projetos, consultoria e assessoria, construção, reforma e ampliação de edificações, desde a fundação até os acabamentos, revitalização de praças, construção de pórticos, entre outras.

A FM possui 36 colaboradores, sendo 34 diretamente alocados nas obras exercendo as funções de mestre de obras, pedreiros, meio oficiais, serventes, pintores, técnico em segurança do trabalho, engenheiro civil e arquiteto de edificações. Além do sócio administrador, o setor administrativo conta com dois colaboradores, nas funções de auxiliar administrativo e técnico em mecânica. A Empresa é de médio porte, tributada pelo Lucro Presumido. A média de seu faturamento mensal é de aproximadamente $\mathrm{R} \$ 270.000,000$ (ano base 2014).

\subsection{Análise da rotatividade}

A empresa objeto de estudo possui um sistema de controle e registro de valores que auxiliam o setor financeiro, contábil e fiscal da empresa. A folha de pagamento e os demais serviços que envolvem o setor de recursos humanos são totalmente terceirizados por um escritório contábil da mesma cidade. A empresa possui um assistente administrativo destinado a auxiliar nas rotinas de um setor de RH e é este quem mantem atualizado um controle interno de admissões e demissões através de planilha eletrônica. Segundo Crepaldi (2013), os controles administrativos fazem parte de um plano de organização e todos os métodos e procedimentos utilizados por eles são para proporcionar eficiência às operações e dar ênfase à política de negócios da empresa.

Para dar início à pesquisa, foi-se até o escritório da empresa fazer uma entrevista com o colaborador responsável pelas rotinas do setor de RH e fez-se um levantamento dos dados disponíveis. Observou-se que a empresa possui este controle de entradas e saídas de funcionários desde o ano de 2004, mas considera-se relevante estudar os últimos 5 anos (2010 a 2014), justamente pelo crescimento apresentado pela empresa neste período.

Para melhor visualizar as entradas e saídas de funcionários no decorrer dos anos de 2010 a 2014, bem como o estoque ativo de funcionários nos períodos, reuniram-se as informações na tabela a seguir. A coluna entradas/saídas refere-se ao volume de funcionários que iniciaram e saíram no mesmo ano. 
Tabela 1: Levantamento de admissões e demissões anuais

\begin{tabular}{lccccc}
\hline ANO & $\begin{array}{c}\text { ATIVOS INÍCIO } \\
\text { DO PERÍODO }\end{array}$ & ADMISSÕES & DEMISSÕES & $\begin{array}{c}\text { ATIVOS FINAL } \\
\text { DO PERÍODO }\end{array}$ & $\begin{array}{c}\text { ENTRADAS/ } \\
\text { SAÍDAS }\end{array}$ \\
\hline 2010 & 11 & 22 & 7 & 26 & 3 \\
2011 & 26 & 54 & 47 & 33 & 29 \\
2012 & 33 & 107 & 73 & 67 & 56 \\
2013 & 67 & 25 & 52 & 40 & 11 \\
2014 & 40 & 34 & 41 & 33 & 16 \\
\hline TOTAIS & $\mathbf{1 7 7}$ & $\mathbf{2 4 2}$ & $\mathbf{2 2 0}$ & $\mathbf{1 9 9}$ & $\mathbf{1 1 5}$ \\
\hline
\end{tabular}

Fonte: Elaborada pelos autores

Observando estes dados, nota-se que nos três primeiros anos a quantidade total de entrada de funcionários era superior às saídas. A partir daí, as demissões superaram as admissões feitas, no qual um número significativo de colaboradores iniciou suas atividades na empresa no mesmo ano de sua saída.

Para complementar estas informações, buscou-se a quantidade de demissões que a empresa teve no período de 2010 a 2014 e os desligamentos que foram efetivados dentro do período de experiência praticado pela empresa (90 dias). Após levantamento, constatou-se que $40 \%$ dos colaboradores que iniciaram na empresa se desligaram dentro do período de três meses, enquanto $60 \%$ permanecem ou permaneceram um período superior ao da experiência. Os $40 \%$ representam 90 funcionários e os $60 \%$ representam 220 funcionários.

Com o intuito de constatar quais as causas da saída de colaboradores da empresa FM, fez-se um levantamento nos registros e documentos da empresa, acerca dos principais motivos, chegando aos seguintes resultados: 29\% dos funcionários desligados saíram da empresa devida uma oferta de emprego mais atrativa. Em seguida, $27 \%$ foram desligados pelo comportamento não condizer com as normas e perspectivas da empresa, como faltas em excesso, desentendimento entre colegas da equipe, não respeitar horários e locais específicos para fumar e não demonstrar competências necessárias para desenvolver os trabalhos de determinada função.

Além disso, chama atenção que $12 \%$ dos funcionários demostraram interesse em requerer o seguro-desemprego e para isto, deixaram de produzir e executar as tarefas solicitadas, consequentemente foram desligados da empresa. Com o mesmo percentual, 7\% apresentam como causa a insatisfação geral, problemas de saúde e problemas pessoais. E por fim, $5 \%$ não se adaptaram ao setor da construção civil e também 5\% foram demitidos pelo término da obra em determinado local. Este índice geralmente é baixo, tendo em vista que a empresa tenta realocar todos seus colaboradores, para que todos tenham a oportunidade de permanecer na empresa.

\subsection{Cálculos do índice de rotatividade - Ir}

Após o levantamento dos dados referente às admissões e demissões da empresa, foi possível aplicar a fórmula para apurar o índice da rotatividade de pessoal. A fórmula escolhida foi a mesma utilizada pelo DIEESE, que a utiliza na divulgação de seus informes, onde através de dados extraídos da RAIS utilizam o valor mínimo entre admitidos e desligados, relacionando-os ao estoque médio de cada período. Assim, para calcular o Ir da empresa FM, utilizou-se no numerador da fórmula, a quantidade de demissões no período de 
2010 a 2012. Já nos anos de 2013 e 2014, utilizou-se o total de admissões, pois conforme o cálculo considera-se o valor mínimo de admitidos e demitidos no período.

Após, optou-se por analisar também os índices nacionais do setor. De acordo com divulgação do DIEESE (2014), a taxa de rotatividade global brasileira na construção civil, (aquela que considera também os desligados por transferência, aposentadoria, morte e demissão voluntária) são de 118,7\% em 2010, 115,7\% em 2011, 114,9\% em 2012 e 115,0\% em 2013. A taxa de rotatividade do ano de 2014 ainda não havia sido divulgada, mas segundo a revista Exame (2015), o ano de 2014 apresentou uma queda no nível de emprego de 0,51\% em comparação ao ano de 2013, com um saldo negativo de 18 mil entre demissões e contratações de trabalhadores formais. O Quadro 1 apresenta um comparativo dos índices da empresa FM com os índices nacionais do setor.

Quadro 1: Comparação FM com índice nacional do setor

\begin{tabular}{|c|c|c|c|}
\hline ANO & FÓRMULA & ÍNDICE FM & $\begin{array}{l}\text { ÍNDICE } \\
\text { BRASIL }\end{array}$ \\
\hline 2010 & $\frac{7}{\frac{(11+26)}{2}} \times 100$ & $37,84 \%$ & $118,70 \%$ \\
\hline 2011 & $\frac{47}{\frac{(26+33)}{2}} \times 100$ & $159,32 \%$ & $115,70 \%$ \\
\hline 2012 & $\frac{73}{\frac{(33+67)}{2}} \times 100$ & $146,00 \%$ & $114,90 \%$ \\
\hline 2013 & $\frac{25}{\frac{(67+40)}{2}} \times 100$ & $46,73 \%$ & $115,00 \%$ \\
\hline 2014 & $\frac{34}{\frac{(40+33)}{2}} \times 100$ & $93,15 \%$ & $*$ \\
\hline
\end{tabular}

Fonte: Elaborada pelos autores

*O índice de rotatividade não havia sido divulgado até o encerramento da pesquisa

Comparando ao setor da construção civil no Brasil, o índice de rotatividade na FM oscilou significativamente a cada período avaliado. No ano de 2010 e 2013, o Ir na empresa foi relativamente baixo confrontando ao do setor, já no período de 2011 e 2012, os índices da empresa ultrapassaram os da construção em média de 37\%. Percebe-se que a maior diferença do índice de rotatividade entre a FM e o setor, ocorreu no ano de 2010, devido à pouca movimentação de pessoas na empresa, tanto de entradas como de saídas. O índice mais próximo ocorreu no ano de 2012, justamente o ano que teve o maior volume de admissões e demissões.

\subsection{Apuração dos gastos decorrentes da rotatividade}

Sempre que ocorre o desligamento de um funcionário na empresa, automaticamente existe a necessidade de substituí-lo, iniciando-se então os processos de reposição e de treinamento do novo colaborador. Cada uma dessas etapas gera custos e reflexos à saúde financeira da empresa, à produtividade e aos negócios. Após levantamento feito dos índices de rotatividade na FM, considera-se relevante explanar os gastos que envolvem todo o processo de desligamento e reposição de pessoal. No decorrer do estudo, os valores

GєCont, v. 4, n. 1, Floriano-PI, Jan-Jun. 2017. 
encontrados serão tratados como gastos, tendo em vista que os mesmos englobam os custos e despesas.

A mensuração dos gastos que envolvem o desligamento de funcionários é de suma importância, visto que através dos resultados é possível avaliar o quanto a empresa é onerada por tal evasão. De acordo com Chiavenato (2006), os custos de desligamento englobam despesas com o órgão de registro e documentação relativa ao processo de desligamento do funcionário, custo da antecipação de pagamentos relacionados com férias proporcionais, $13^{\circ}$ salário proporcional, aviso prévio, multa do FGTS e outros.

Com base nestas informações, apurou-se os principais custos e gastos que a FM tem com o desligamento de um funcionário, seja por demissão da empresa, por iniciativa do colaborador ou por término de contrato de trabalho.

Tabela 2: Gastos de Desligamento - em R\$

\begin{tabular}{lrrrrrr}
\hline GASTO & $\mathbf{2 0 1 0}$ & $\mathbf{2 0 1 1}$ & $\mathbf{2 0 1 2}$ & $\mathbf{2 0 1 3}$ & $\mathbf{2 0 1 4}$ & \multicolumn{1}{c}{ TOTAL } \\
\hline Exame demissional & 280,00 & $1.880,00$ & $3.650,00$ & $4.420,00$ & $4.510,00$ & $14.740,00$ \\
Rescisão & 568,47 & $4.104,04$ & $6.845,94$ & $5.345,08$ & $4.516,56$ & $21.380,09$ \\
Multa FGTS & $2.723,25$ & $13.629,32$ & $13.648,94$ & $21.798,43$ & $22.926,27$ & $74.726,21$ \\
Aviso Indenizado & $3.840,00$ & $22.097,09$ & $14.245,41$ & $8.292,36$ & $2.834,40$ & $51.309,26$ \\
Déc. Terc. Aviso Ind. & 320,00 & $1.794,94$ & $1.160,20$ & 683,73 & 236,20 & $4.195,07$ \\
Férias Aviso Ind. & 426,67 & $2.393,25$ & $1.546,93$ & 879,87 & 340,48 & $5.587,20$ \\
\hline TOTAL & $\mathbf{8 . 1 5 8 , 3 9}$ & $\mathbf{4 5 . 8 9 8 , 6 4}$ & $\mathbf{4 1 . 0 9 7 , 4 2}$ & $\mathbf{4 1 . 4 1 9 , 4 7}$ & $\mathbf{3 5 . 3 6 3 , 9 1}$ & $\mathbf{1 7 1 . 9 3 7 , 8 3}$ \\
\hline
\end{tabular}

Fonte: Elaborada pelos autores

Merece destaque que a maioria das rescisões da FM são de iniciativa da própria empresa, o que pode ser verificado na Tabela 2, onde a multa de FGTS representa o gasto mais oneroso do levantamento feito. Ressalta-se que o valor da multa do FGTS é o total da GRRF, com base no saldo dos depósitos do fundo de garantia, do aviso prévio e da multa rescisória.

Já os gastos relacionados à reposição de pessoas, por sua vez, incorrem numa organização quando acontece a substituição de um trabalhador por outro. Seguindo a linha de pensamentos de Cascio e Baudreau (2010), fez-se um levantamento dos gastos de reposição na empresa FM, conforme Tabela 3.

Tabela 3: Gastos de Reposição - em R \$

\begin{tabular}{lrrrrrr}
\hline GASTO & $\mathbf{2 0 1 0}$ & $\mathbf{2 0 1 1}$ & $\mathbf{2 0 1 2}$ & $\mathbf{2 0 1 3}$ & $\mathbf{2 0 1 4}$ & \multicolumn{1}{c}{ TOTAL } \\
\hline Anúncio Jornais e Rádios & 20,00 & 30,00 & 15,00 & 45,00 & 227,50 & 337,50 \\
Recrutamento e seleção & 702,00 & $1.948,91$ & $4.505,67$ & $1.129,09$ & $1.698,15$ & $9.983,82$ \\
Exame admissional & 550,00 & $1.350,00$ & $3.210,00$ & $1.500,00$ & $2.720,00$ & $9.330,00$ \\
Outros exames & 330,00 & $1.242,00$ & $5.885,00$ & $3.000,00$ & $5.440,00$ & $15.897,00$ \\
Admissão & 893,64 & $2.358,18$ & $5.018,30$ & $1.285,25$ & $1.873,40$ & $11.428,77$ \\
Primeiras instruções & 90,00 & 343,64 & 875,45 & 204,55 & 355,45 & $1.869,09$ \\
Kit EPI’s & $3.117,40$ & $8.453,16$ & $19.463,30$ & $5.075,50$ & $9.562,50$ & $45.671,86$ \\
\hline TOTAL & $\mathbf{5 . 7 0 3 , 0 4}$ & $\mathbf{1 5 . 7 2 5 , 8 9}$ & $\mathbf{3 8 . 9 7 2 , 7 2}$ & $\mathbf{1 2 . 2 3 9 , 3 9}$ & $\mathbf{2 1 . 8 7 7 , 0 0}$ & $\mathbf{9 4 . 5 1 8 , 0 4}$ \\
\hline
\end{tabular}

Fonte: Elaborada pelos autores

Cabe destacar que, ao iniciar as atividades na empresa, o novo colaborador recebe um kit de equipamentos de proteção individual, no qual contém: capacete de proteção, luva de raspa, luva de neoprene, óculos de proteção lentes clara e escura, protetor auricular, uniforme (calça de sarja e camiseta), sapato de proteção, cinto de segurança, respirador e protetor solar.

GєCont, v. 4, n. 1, Floriano-PI, Jan-Jun. 2017. 
Ao receber o kit, cada colaborador assina um termo de responsabilidade pelo material recebido e compromete-se a devolver os EPI's caso ocorra o desligamento da empresa. Conforme a Tabela 3, verifica-se que os equipamentos de proteção individual são os gastos com maior representatividade em valores. Segundo Cascio e Baudreau (2010), os funcionários substituídos precisam ser instruídos e treinados para adquirirem competências de assumir sua função dentro da empresa. $\mathrm{Na} \mathrm{FM}$, os funcionários passam por três treinamentos na empresa, o treinamento da NR 35 - Trabalho em Altura, treinamento repassado pelo técnico em segurança do trabalho e treinamento do mestre de obras no local da obra no qual o novo funcionário será alocado. O treinamento da NR 35 - Trabalho em Altura, atende à Portaria da Secretaria de Inspeção do Trabalho no 313 de 23 de março de 2012.

A empresa FM possui assessoria de uma empresa especializada em saúde ocupacional desde junho de 2010. É ela quem elabora os Laudos de Saúde Ocupacional, além de disponibilizar o médico do trabalho para os atestados de saúde ocupacional e é responsável pelos treinamentos dos colaboradores. Os colaboradores da FM receberam o treinamento da NR-35 a partir do ano de 2013 e o mesmo é ministrado pela empresa de assessoria.

Devido ao alto custo e ao giro de mão de obra, não são todos os colaboradores da empresa que recebem o treinamento. Somente são treinados os funcionários que possam ter envolvimento com atividades acima do primeiro pavimento, como desenforme de formas, concretagem, pintura do prédio, acabamentos externos, execução de serviços no telhado e revestimento de alvenarias.

No ano de 2011, a FM obteve a necessidade de contratar um funcionário para a função de técnico em segurança do trabalho, por cumprimento de exigência de contrato de uma obra e por constatar a importância da segurança do trabalho na construção civil, devido os riscos que o setor está sujeito. "O crescimento acentuado da construção civil, verificado nos últimos anos em todo o país, tem sido acompanhado pelo aumento do número de acidentes de trabalho e de mortes de operários, principalmente por soterramento, queda ou choque elétrico". (ALTAFIN, 2013).

Após a assinatura do contrato de experiência 90 (noventa dias), o colaborador é encaminhado para obra e lá é recepcionado pelo técnico em segurança do trabalho. É o técnico quem repassa o treinamento básico sobre as normas de segurança do trabalho, do uso dos equipamentos de proteção individual e coletivo, o manuseio correto e seguro dos equipamentos (guinchos, serras, furadeiras e outros), a prevenção de acidentes de trabalho e os riscos da construção civil, além de mostrar in loco o funcionamento da obra.

Logo após o treinamento do técnico em segurança do trabalho, o novo colaborador é encaminhado ao mestre de obras, que lhe passará as primeiras instruções das atividades que deverão ser executadas no decorrer da construção. Caso o funcionário já tenha experiência, o mesmo inicia suas atividades logo em seguida. Caso contrário, inicia-se um treinamento para a execução das tarefas diárias e como funcionam os equipamentos que são utilizados em tal função. A partir dos dados coletados na empresa, fez-se um levantamento dos gastos com treinamento de novos funcionários, conforme Tabela 4.

Tabela 4: Treinamento na Empresa FM - em R\$

\begin{tabular}{lrrrrrr}
\hline GASTO & $\mathbf{2 0 1 0}$ & $\mathbf{2 0 1 1}$ & $\mathbf{2 0 1 2}$ & $\mathbf{2 0 1 3}$ & $\mathbf{2 0 1 4}$ & \multicolumn{1}{c}{ TOTAL } \\
\hline Treinam. NR 35 & - & - & - & $1.250,00$ & $1.750,00$ & $3.000,00$ \\
Treinam. seg. trab. & - & 540,00 & $1.264,55$ & 363,64 & 370,91 & $2.539,09$ \\
Treinamento obra & $3.630,00$ & $10.800,00$ & $25.680,00$ & $7.750,00$ & $10.540,00$ & $58.400,00$ \\
\hline TOTAL & $\mathbf{3 . 6 3 0 , 0 0}$ & $\mathbf{1 1 . 3 4 0 , 0 0}$ & $\mathbf{2 6 . 9 4 4 , 5 5}$ & $\mathbf{9 . 3 6 3 , 6 4}$ & $\mathbf{1 2 . 6 6 0 , 9 1}$ & $\mathbf{6 3 . 9 3 9 , 0 9}$ \\
\hline
\end{tabular}

Fonte: Elaborada pelos autores 
$\mathrm{Na}$ Tabela 4 constam os gastos que a empresa absorve para treinar os novos funcionários. A empresa FM iniciou o treinamento da NR-35 aos seus funcionários em 2013. O treinamento teórico e prático, com duração de oito horas, possui um custo de $\mathrm{R} \$ 250,00$ por pessoa. Após um levantamento de dados, apurou-se que em 2013 somente cinco funcionários receberam o treinamento e, em 2014, foram qualificados apenas 7 colaboradores. No ano de 2011, foi incluído no quadro de funcionários da empresa FM o técnico em segurança do trabalho. O tempo médio para repassar o treinamento de segurança do trabalho e mostrar a obra é de 2 horas. Neste período o novo funcionário recebe instruções referente à segurança e os riscos da obra, além de conhecer a equipe de trabalho e as acomodações, como refeitório, sanitários, locais para fumar no intervalo e para o uso de celular.

Para mensurar o custo do treinamento em segurança do trabalho, apurou-se o salário do técnico em segurança, dividiu-se pelas 220 horas mensais e multiplicou-se por 2 horas de tempo da duração do treinamento. No cálculo, não se considerou os encargos, caso contrário, o valor seria ainda maior.

Em continuidade ao processo de treinamento, o novo colaborador é encaminhado ao mestre de obras. É o mestre quem avalia a duração do treinamento, considerando a experiência anterior ou não do recém-contratado. Geralmente este treinamento tem duração de 20 horas, podendo variar para mais ou para menos dependendo do nível de aprendizagem do novo funcionário. Os custos relacionados ao treinamento na obra foram calculados com base no valor da hora do mestre de obras (sem considerar os encargos), multiplicando-se pelo tempo gasto com o treinamento. Ao analisar a Tabela 4, pode-se constatar que o treinamento mais oneroso para a empresa é o treinamento repassado pelo mestre de obras, representando mais de $80 \%$ dos custos considerando o total, no decorrer de todos os anos.

\subsection{Análises comparativas dos gastos com a rotatividade}

Conforme Silva (2010), a análise financeira é uma ferramenta que auxilia na avaliação da empresa, tanto em seu contexto operacional como estratégico. O mercado remete a necessidade de compreensão dos objetivos, das atividades e dos resultados das organizações, bem como das condições e fatores que os influenciam. Ainda segundo o mesmo autor, a análise financeira de uma empresa consiste num exame minucioso dos dados financeiros disponíveis, onde a avaliação dos resultados possibilita a correção da rota da empresa, caso seja necessário. Com base nisto, fez-se a composição total dos gastos que envolvem a rotatividade de colaboradores, para que fosse possível fazer uma análise financeira na FM e apurar em quanto a rotatividade está prejudicando a saúde financeira da empresa.

Tabela 5: Composição total dos gastos com rotatividade - em R\$

\begin{tabular}{lrrrrrr}
\hline GASTO & $\mathbf{2 0 1 0}$ & $\mathbf{2 0 1 1}$ & $\mathbf{2 0 1 2}$ & $\mathbf{2 0 1 3}$ & $\mathbf{2 0 1 4}$ & \multicolumn{1}{c}{ TOTAL } \\
\hline Gastos desligamento & $8.158,39$ & $45.898,64$ & $41.097,42$ & $41.419,47$ & $35.363,91$ & $171.937,83$ \\
Gastos reposição & $5.703,04$ & $15.725,89$ & $38.972,72$ & $12.239,39$ & $21.877,00$ & $94.518,04$ \\
Gastos treinamentos & $3.630,00$ & $11.340,00$ & $26.944,55$ & $9.363,64$ & $12.660,91$ & $63.939,09$ \\
\hline TOTAL & $\mathbf{1 7 . 4 9 1 , 4 3}$ & $\mathbf{7 2 . 9 6 4 , 5 3}$ & $\mathbf{1 0 7 . 0 1 4 , 6 9}$ & $\mathbf{6 3 . 0 2 2 , 5 0}$ & $\mathbf{6 9 . 9 0 1 , 8 1}$ & $\mathbf{3 3 0 . 3 9 4 , 9 6}$ \\
\hline
\end{tabular}

Fonte: Elaborada pelos autores

Observando a Tabela 5, percebe-se que o gasto com desligamento é o processo mais oneroso para a empresa no decorrer dos anos, seguido pelo gasto com reposição e treinamentos. O ano de 2012 foi o ano que apresentou o maior valor total relacionado aos gastos da rotatividade, prejudicando financeiramente a empresa em R \$ 107.014,69. Para verificar a relevância destes valores, fez-se um comparativo entre o faturamento anual da FM e os gastos totais anuais que envolvem a rotatividade de funcionários, conforme Tabela 6.

GєCont, v. 4, n. 1, Floriano-PI, Jan-Jun. 2017. 
Tabela 6: Comparação faturamento anual $\mathrm{x}$ gastos com rotatividade

\begin{tabular}{lccc}
\hline ANO & FATURAMENTO & GASTOS TOTAIS & \% \\
\hline 2010 & $3.275 .119,15$ & $17.491,43$ & 0,53 \\
2011 & $3.333 .690,96$ & $72.964,53$ & 2,19 \\
2012 & $5.872 .965,04$ & $107.014,69$ & 1,82 \\
2013 & $6.785 .360,57$ & $63.022,49$ & 0,93 \\
2014 & $3.286 .471,73$ & $69.901,82$ & 2,13 \\
\hline TOTAL & $\mathbf{2 2 . 5 5 3 . 6 0 7 , 4 5}$ & $\mathbf{3 3 0 . 3 9 4 , 9 6}$ & $\mathbf{1 , 4 6}$ \\
\hline
\end{tabular}

Fonte: Elaborada pelos autores

Relacionando os valores encontrados na Tabela 6 com o faturamento anual da FM, pode-se apurar que em 2010 o percentual de representatividade dos gastos com a rotatividade em relação ao faturamento foi de 0,53\%. Em 2011 o percentual elevou-se para 2,19\%, reduzindo para 1,82\% em 2012, 0,93\% em 2013 e aumentando novamente em 2014 para $2,13 \%$. O percentual total de representatividade sobre os 5 anos foi de $1,46 \%$ sobre o faturamento.

Além disso, comparou-se os gastos encontrados com o resultado financeiro desejado pela empresa, visto que quando selado um contrato, a empresa estipula uma meta de $10 \%$ (média) a ser atingida de resultado financeiro. Sobre esta meta, as compras e os gastos da empresa são controlados a fim de que ao final de cada obra, sobre o percentual definido.

Tabela 7: Comparação resultado $\mathrm{x}$ gastos totais

\begin{tabular}{lccc}
\hline ANO & RESULTADO & GASTOS TOTAIS & \% \\
\hline 2010 & $327.511,92$ & $17.491,43$ & 5,34 \\
2011 & $333.369,10$ & $72.964,53$ & 21,89 \\
2012 & $587.296,50$ & $107.014,69$ & 18,22 \\
2013 & $678.536,06$ & $63.022,49$ & 9,29 \\
2014 & $328.647,17$ & $69.901,82$ & 21,27 \\
\hline TOTAL & $\mathbf{2 . 2 5 5 . 3 6 0 , 7 5}$ & $\mathbf{3 3 0 . 3 9 4 , 9 6}$ & $\mathbf{1 4 , 6 5}$ \\
\hline
\end{tabular}

Fonte: Elaborada pelos autores

Conforme Tabela 7, pode-se observar que o percentual total entre a relação de representatividade dos gastos envolvendo somente a rotatividade de pessoas e o resultado financeiro almejado pela FM foi de 14,65\%. O ano de 2013 fora o período que se almejou a maior margem de resultado, tendo em vista o volume de obras contratadas. Já em 2014, a margem de resultado diminuiu-se pela metade, sendo que os gastos com a rotatividade em 2013 e 2014 praticamente se equivaleram. Com isso, o percentual de representação em 2013 foi somente de 9,29\%, já em 2014 o percentual elevou-se para 21,27\%.

Ademais, os valores que envolvem a rotatividade de funcionários, poderiam estar sendo utilizados para cobrir outros custos, como por exemplo, o combustível dos veículos (custo variável indireto) que transportam os colaboradores até as obras ou então o salário do arquiteto de edificações (custo fixo indireto). Somente no ano de 2014, o gasto total com rotatividade, poderia abastecer todos os veículos da empresa pelo período de quase dois anos ou então, pagar mais de seis meses de salário do arquiteto de edificações.

É de suma importância fazer esta análise financeira dos gastos com a rotatividade de pessoal, tendo em vista que através destes resultados é possível verificar os valores exatos que estão sendo gastos com desligamento, reposição e treinamento de funcionários. Ademais, é possível fazer uma reavaliação nos processos, na tentativa de diminuir tais gastos, que 
poderiam estar sendo utilizados, por exemplo, em futuros investimentos, revertidos em mais benefícios aos colaboradores ou ainda, em uma maior margem de lucro aos sócios.

\section{CONCLUSÃO}

Após a coleta de dados, foi possível avaliar todo o processo de rotatividade de funcionários na empresa FM, desde suas causas até a mensuração dos gastos. Foi importante fazer o levantamento mensal das admissões e demissões no decorrer dos anos de 2010 a 2014, visto que foi possível acompanhar a movimentação mês a mês do volume efetivo de funcionários.

Além disso, quantificou-se um total de 115 colaboradores que deram entrada e saíram no mesmo ano na empresa, volume consideravelmente alto se comparado as 242 admissões e 220 demissões no período dos 5 anos. Apurou-se também, que destes 115 colaboradores, 90 saíram nos três primeiros meses, ou seja, ainda no período de experiência praticado pela empresa.

Através dos procedimentos metodológicos anteriormente descritos, foram identificadas as principais causas da rotatividade na FM no ano de 2014, sendo que ofertas mais atrativas estão no topo com $29 \%$ dos motivos que incentivam a evasão. É necessário haver um estudo referente aos motivos que levam a tal fenômeno, para que possam ser encontradas possíveis soluções de estagnação da rotatividade.

Os índices de rotatividade apurados na FM foram relativamente. Pela fórmula utilizada pelo DIEESE, a média encontrada na empresa foi de $96 \%$. Não há um índice ideal de rotatividade, mas sabe-se que elevadas taxas podem afetar a saúde financeira da empresa, bem como prejudicar o processo produtivo.

No levantamento realizado dos gastos com desligamento, apurou-se que a empresa FM gastou R\$ 171.937,83 nos anos de 2010 a 2014. Percebe-se que os gastos mais elevados foram com multas do FGTS e indenizações de aviso prévio. Os anos de 2011, 2012 e 2013 foram os anos que apresentaram o maior volume de demissões e por consequência, o período que mais onerou a FM.

No processo de reposição, verificou-se os valores gastos para substituir um colaborador, sem considerar a perda de produtividade nas obras. Foram avaliados gastos desde a captação de mão de obra através dos meios de comunicação, até custos relacionados à efetiva admissão e elementos fundamentais para subsidiar a segurança dos novos colaboradores. Estima-se que o ano de 2012 foi o período com os mais altos gastos, sendo que os equipamentos de proteção são destaque nos 5 anos como o gasto com maior representatividade.

Ao coletar informações referente à capacitação dos funcionários na FM, identificou-se três treinamentos aplicados. O treinamento com menor representatividade de gastos é o repassado pelo técnico em segurança do trabalho, mas não menos importante, visto que através dele podem ser evitados acidentes de trabalho nas obras. $\mathrm{O}$ treinamento transmitido pelo mestre de obras é o que mais onera a empresa, tendo em vista o alto valor hora do mestre, justamente pela experiência e habilidade na função.

O treinamento da NR 35 possui uma representatividade baixa nos gastos com treinamento, mas estes valores só são baixos pelo fato da empresa capacitar apenas os funcionários que exercem atividades em altura. Caso a FM capacitasse todos os seus colaboradores com a NR 35, este treinamento oneraria a empresa em mais de $40 \%$ no decorrer dos anos de 2012 a 2014.

Ao analisar a composição total dos gastos que envolvem a rotatividade de funcionários, deparou-se com um gasto financeiro total de $\mathrm{R} \$ 330.394,96$. Além disso, ao comparar os gastos totais no decorrer dos 5 anos com o faturamento da FM, têm-se a 
percepção de que os gastos são irrelevantes em contraponto à receita anual. Mas, na comparação dos gastos totais com o resultado desejado pela FM, obtêm-se dados mais plausíveis de comparação, haja vista que os valores envolvidos no processo da rotatividade atingem principalmente os resultados desejados pela organização. A análise financeira numa entidade sistematiza as informações contábeis e agrega outros aspectos relevantes que auxiliam os gestores na avaliação para tomada de decisões e na orientação de suas ações.

Foi possível constatar que outras ofertas mais atrativas de emprego foram a principal causa da rotatividade na FM. Além disso, os índices encontrados estão relativamente altos em confronto aos do setor da construção civil. Caso a empresa obtivesse êxito na diminuição dos índices de rotatividade, ela poderia investir os valores gastos no processo de reposição em outras áreas de interesse.

A carência de informações relativas a indicadores de gestão de recursos humanos das empresas da região foi uma limitação do estudo, pois permitiria uma comparação com empresas do mesmo setor, até mesmo com outros ramos de atividade. Nesse sentido, recomenda-se para trabalhos futuros, que sejam aplicados os indicadores de gestão de recursos humanos para haver o acompanhamento do desenvolvimento individual, comparando resultados de diferentes períodos e identificando pontos de melhoria para impulsionar ações de transformação. Além disso, estudos envolvendo sistemas de custeio na atividade da construção civil, visto que há uma carência de pesquisas nessa área.

\section{REFERÊNCIAS}

ALTAFIN, Iara Guimarães. Número de acidentes de trabalho na construção civil preocupa especialistas. Senado Notícias. Disponível em:

http://www12.senado.leg.br/noticias/materias/2013/03/11/numero-de-acidentes-de-trabalhona-construcao-civil-preocupa-especialistas Acesso em 07 abr. 2015.

MTE - MINISTÉRIO DO TRABALHO E EMPREGO. Dados e Estatísticas de 2014. 2014. Disponível em: http://portal.mte.gov.br/caged/ Acesso em: 30 mar. 2015.

CAMPOS, Claudia Valentina de Arruda; MALIK, Ana Maria. Satisfação no trabalho e rotatividade dos médicos do Programa de Saúde da Família. Rev. Adm. Pública, v. 42, n. 2, 2008.

CARDOSO, Maurício Farias; CARDOSO, Janice de Freitas; SANTOS, Simone Rodrigues dos. O impacto da rotatividade e do absenteísmo de pessoal sobre o custo do produto: um estudo em uma indústria gaúcha. Rev. de Gestão, Finanças e Contabilidade, Salvador, v. 3, n. 1, p. 107-121, 2013.

CASCIO, W; BOUDREAU, J. Investimento em pessoas. Porto Alegre: Bookmann, 2010.

CHIAVENATO, Idalberto. Gerenciando com as pessoas. Rio de Janeiro: Elsevier, 2004.

Gestão de Pessoas. 3. ed. Rio de Janeiro: Elsevier, 2010.

Planejamento, Recrutamento e Seleção de Pessoal. Como

Agregar Talentos à Empresa. 6. ed. São Paulo: Atlas, 2006.

GєCont, v. 4, n. 1, Floriano-PI, Jan-Jun. 2017. 
Remuneração, benefícios e relações de trabalho: como reter talentos na organização. 6 ed. rev. e atual. Barueri, São Paulo: Manole, 2009.

CREPALDI, Sílvio Aparecido. Auditoria contábil: teoria e prática. 9 ed. São Paulo: Atlas, 2013.

CSB - Central dos Sindicatos Brasileiros. Rotatividade cai na construção, mas ainda supera 6\% ao mês. Disponível em: http://csbbrasil.org.br/rotatividade-cai-na-construcaomas-ainda-supera-6-ao-mes/. Acesso em: 03 out 2014.

DEDECCA, Claudio Salvadori; BALTAR, Paulo Eduardo de Andrade. Mercado de trabalho e informalidade nos Anos 90. Est. Econ. São Paulo: 1997. 65 - 84 p. Disponível em: http://pt.scribd.com/doc/145559095/Mercado-Trabalho-Informalidade-90s-DEDECCA. Acesso em: 27 set. 2014.

DIAS, Manoel. Ministro abre I Seminário sobre rotatividade no mercado de trabalho. Disponível em: http://portal.mte.gov.br/imprensa/ministro-abre-i-seminario-sobrerotatividade-no-mercado-de-trabalho.htm. Acesso em: 09 nov 2014.

DIEESE - Departamento Intersindical de Estatística e Estudos Socioeconômicos. Boletim Trabalho e Construção. O Trabalhador e a inserção ocupacional na construção e suas divisões. Dez 2012 - n 7. 14 p. Disponível em:

http://www.dieese.org.br/boletimtrabalhoeconstrucao/2012/2012boletimTrabalhoConstrucao7 .pdf. Acesso em: 11 out 2014.

Boletim Trabalho e Construção. Salários na Construção Civil nos anos 2000: entre a formalização e a rotatividade. Dez $2011-\mathrm{n}^{\circ}$ 6. p. 07.Disponível em: http://www.dieese.org.br/boletimtrabalhoeconstrucao/2011/2011boletimTrabalhoConstrucao6 .pdf. Acesso em: 11 out 2014.

.Os números da Rotatividade no Brasil: Um olhar sobre os dados da Rais 2002 - 2013. DIEESE, 2014. 17 p. Disponível em: http://www.dieese.org.br/notaaimprensa/2014/numerosRotatividadeBrasil.pdf Acesso em 30 mar 2015.

ECKERT, Alex; MECCA, Marlei Salete; DENICOL, Maria Salete Goulart Martins; GIACOMET, Mônica Oliveira. As motivações e os reflexos do turnover em termos contábeis e econômicos numa entidade sem fins lucrativos no município gaúcho de Caxias do Sul. In: XIII Convenção de Contabilidade do Rio Grande do Sul. Gramado - RS. Trabalhos Científicos, 2011.

FREZATTI, Fábio. Gestão da Viabilidade Econômico-Financeira dos Projetos de Investimento. São Paulo: Atlas, 2008.

GIL, Antonio Carlos. Como elaborar projetos de pesquisa. 5. ed. São Paulo: Atlas, 2010.

GONZAGA, Gustavo. Rotatividade e qualidade do emprego no Brasil. Revista de Economia Política, vol 18, n1, janeiro - março 1998. 120 - 140 p. Disponível em:

http://www.rep.org.br/pdf/69-8.pdf. Acesso em: 10 ago 2014. 
MARCONDES, Carlos Gustavo Nastari. Programas de Qualificação de mão de obra. Série de Cadernos Técnicos da Agenda Parlamentar - Crea PR, 2011, 24 p. Disponível em: http://www.crea-

pr.org.br/index.php/index.php?option=com_phocadownload\&view=category \&download=546 :programas-de-qualificacao-de-mao-de-obra\&id=37: cadernos-tecnicos \&Itemid=95. Acesso em: 27 set. 2014.

MARIANO, Sandra Regina Holanda; MAYER, Verônica Feder (Org.). Modernas práticas na gestão de pessoas. Rio de Janeiro: Elsevier, 2008.

MEDEIROS, Rochele Kaline Reis de; ALVES, Rafaela da Cunha; RIBEIRO, Sidney Roberto S. Turnover: Uma análise dos fatores que contribuem para a decisão de sair da empresa dos colaboradores da Alfa Comércio Ltda. Revista Connexio, 2012. 115 - 126, 2014.

MILKOVICH, George T. BOUDREAU, John W. Administração de recursos humanos. São Paulo: Atlas, 2012.

MÜLLER, Heitor José. Empregar é caro. Indústria em Ação. Ano 7 - nº 76 - março 2013.

NR-35 TRABALHO EM ALTURA. Portaria SIT nº 313, de 23 de março de 2013. Disponível em: http://portal.mte.gov.br/data/files/8A7C816A3D63C1A0013DAB8EA3975DDA/NR35\%20(Trabalho\%20em\%20Altura).pdf Acesso em: 09 abr 2015.

PONTES, Benedito Rodrigues. Planejamento, recrutamento e seleção de pessoas. 3. ed. São Paulo: LTr, 2001.

EXAME. Número de empregados na construção civil encolheu, dia a FGV. 2014.

Disponível em: http://exame.abril.com.br/economia/noticias/numero-de-empregados-naconstrucao-encolheu-em-2014-diz-a-fgv Acesso em: 31 mar. 2015.

RIBEIRO, José Luís. Construção Civil: breve análise. 2011. Disponível em: http://www.administradores.com.br/producao-academica/construcao-civil-breveanalise/3822/. Acesso em: 04 set. 2014.

RICHARDSON, R. J. Pesquisa social: métodos e técnicas. 3. ed. São Paulo: Atlas, 1999.

SESCON RS - Sindicato das Empresas de Serviços Contábeis e das Empresas de Assessoramento, Perícias, Informações e Pesquisas do Estado do Rio Grande do Sul. Tabela Referencial. 2015. Disponível em: http://www.sescon-rs.com.br/ Acesso em: 23 mar. 2015.

SILVA, Glenio Luiz da Rosa e. Controle do Turnover: Como Prevenir e Demitir com Responsabilidade. Rio de Janeiro: Qualitymark, 2001.

SILVA, José Pereira da. Análise Financeira das Empresas. 10. ed. São Paulo: Atlas, 2010.

YIN, Robert K. Estudo de caso: planejamento e métodos. 4. ed. Porto Alegre: Bookman, 2010. 